\title{
Experimental study on the spatial variation of hydrodynamic parameters for hillslope-gully side erosion system in loess landscapes
}

\author{
XUNGUI LI ${ }^{1} \&$ XIA WEI ${ }^{2}$ \\ 1 College of Earth and Environmental Sciences, Lanzhou University, Lanzhou, Gansu Province, 730000, China \\ lixung@,lzu.edu.cn \\ 2 College of Earth and Environmental Sciences \& Center for Dryland Water Resources Research and Watershed \\ Science, Lanzhou University, Lanzhou, Gansu Province, 730000, China \\ weix@1zu.edu.cn
}

\begin{abstract}
On the Chinese Loess Plateau many hydraulic parameters related to soil erosion are highly variable and often cross-correlated. Hillslope-gully side erosion systems are widespread on the Loess Plateau, but the quantification between the hydraulic parameters is still unknown for the system. A constant headwater scouring experiment in the laboratory was performed in this study and combined a model with two slope segments (with hillslope and gully sides). Five inflow rates of $6,8,10,12$ and $14 \mathrm{~L} / \mathrm{min}$ were used. Some hydraulic parameters (the flow velocity, shear stress, unit stream power, Reynolds Number, Froude Number, Darcy-Weisbach friction factor, and Manning coefficient) were analysed. Regression equations were developed for the parameters. The results provide a basis for in-depth research regarding the erosion processes of hillslope-gully side erosion systems.
\end{abstract}

Key words hillslope-gully side erosion system; hydrodynamic parameters; flow dynamics; flow pattern; flow friction

\section{INTRODUCTION}

Soil erosion is one of the most severe eco-environmental problems worldwide (Pan and Shangguan, 2006). Soil erosion deteriorates soil (Marques et al., 2008), decreases land productivity (Lantican et al., 2003) and degrades streams, lakes and estuaries as sediments and pollutants are transported to them. Due to its thick but loose and fine soil, loess hilly areas around the world, but especially in China, have suffered from severe soil and water loss (Fu et al., 2011). Thus, loess hilly areas are very fragile and the main source of sediments to the Yellow River. Along with the national strategy for developing Western China, environmental issues, such as soil loss and non-point source pollution, have recently attracted greater attention in the Chinese Loess Plateau ( $\mathrm{Li}$ et al., 2009). Research regarding the erosion sediment yield law is critical for understanding sediment yield mechanisms in river basins. The sediment yield law controls the source of watershed sediments and restores the ecological environment in areas with soil and water loss. It is also important to establish a soil erosion forecast model evaluating the watershed soil and water loss environment and predicting its development. As a basic unit in the Loess Plateau, the scale of the hillslope-gully side erosion system is between the slope and the watershed. Thus the system is critical to evaluate and control soil loss on the Loess Plateau. However, research related to the system remains limited. Some research only focused on hillslopes (Nearing et al., 1997). Recently, more and more researchers have realized that hillslopes and gully sides are inseparable and that dealing with just hillslopes or with gully sides cannot reflect soil erosion accurately for an erosion system (Li et al., 2009). Much literature has selected parameters to reflect the hydrodynamic processes of sediment yield, such as flow depth (Merz, 1990), total discharge, discharge per unit width (Meyer et al., 1975), flow shear stress, effective flow shear stress (Nearing et al., 1997), runoff kinetic energy (Bagnold, 1977), effective runoff kinetic energy (Govers, 1992), unit stream power (Moore and Burch, 1986), the Reynolds number and the Froude number (Fr) (De Ploey, 1983). But the knowledge about what characteristics these parameters have and how they influence the soil erosion process is still limited, which results in some problems in the Loess Plateau (Gong et al., 2011). This study aims to reveal the characteristics of the seven main hydraulic parameters and analyse the relationships between them with a laboratory simulation experiment. The main novelty and contribution of this study lies in the systematic and original integration of the hillslope with the gully side as a whole soil erosion system to determine the characteristics of hydraulic parameters controlling soil erosion processes in 
a lab experiment with a simulation model design. The results provide insights to further uncover the real sediment yield law in the Loess Plateau, China.

\section{EXPERIMENTAL DESIGN AND METHODS}

\section{Model design of the hillslope-gully side erosion system}

In the Chinese Loess Hilly Area, the entire sloping surface is divided into either the hillslope or gully side (Li et al., 2009). According to the real situation in the Loess Plateau, the hillslope gradient is $10^{\circ} \sim 35^{\circ}$ and the gully slope is approximately $40^{\circ} \sim 60^{\circ}$ for wasteland and $25^{\circ} \sim 35^{\circ}$ for arable land. The experimental soil box for the hillslope-gully side erosion system was designed based on this information, the principle lab design, and the Chinese Policy of Reforestation (i.e. that farm land with slope greater than $25^{\circ}$ must be changed to forest or grass lands). The hillslopes and gully side erosion system is set as the sketch shown in Fig. 1.

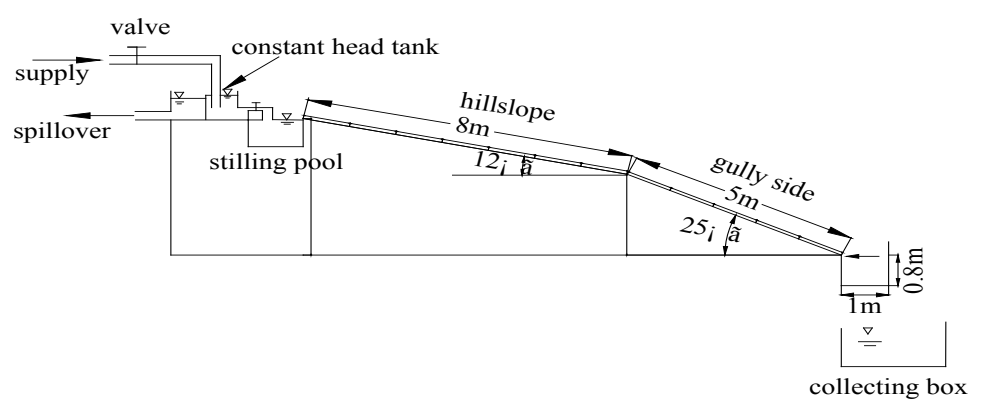

Fig. 1 The experimental soil bed of the hillslope-gully side erosion system

\section{Experimental set-up}

The constant-head water scouring experiments were conducted in the Rainfall Flood Erosion Hall of the Northwest Water Resources and Environment Ecology Key Lab of the Chinese Ministry of Education (MOE) at Xi' an University of Technology, Shaanxi Province, China. The experimental soil box was divided into two experimental portions by PVC boards. Each portion was $13 \mathrm{~m}$ long, $0.5 \mathrm{~m}$ wide and $0.5 \mathrm{~m}$ deep. The top section was $1 \mathrm{~m}$ long and was used as a transition zone. The remaining 12-m long sections were used as test zones (Fig. 1). A loessial loam soil was collected for this experiment from unfarmed land in a suburb of Xi'an. The particle size distribution of this soil is presented in Table 1. The final packed bulk density of the soil in the soil box was $1.25 \mathrm{~g} / \mathrm{cm}^{3}$. The soil moisture content was 10\% (gravimetric), and the box was watertight and equipped with a drainage system. Before the experiment, a layer of fibre was placed in the soil box. Then a natural sand bed of $20 \mathrm{~cm}$ was placed on the fibre layer. The soil bed was wetted by spraying with water until the soil was saturated and no runoff water appeared. This process resulted in uniform initial soil water conditions with evenly distributed stress. The soil box was repacked for each experiment. The experiment involved five scouring inflow rates $(6,8,10,12$ and $14 \mathrm{~L} / \mathrm{min})$, and the duration of each treatment was approximately $30 \mathrm{~min}$. Clear water was introduced to the upper end of the soil bed from the stabilization pond (stilling pool) during saturated conditions. The water temperature in the pond was measured and the flow velocities were measured at each metre with the dye method (using potassium permanganate as a dye) across the entire hillslope-gully side erosion system (Guo, 2013). Flow surface width was measured across the entire hillslope-gully side erosion system at every metre with a steel ruler. Runoff and sediment samples were collected every 1 min with a $10 \mathrm{~L}$ plastic bucket. Each experimental treatment was replicated.

Table 1 Particle size classes of the experimental soil.

\begin{tabular}{lllllllll}
\hline Particle size $(\mathrm{mm})$ & $<0.005$ & $0.005-0.01$ & $0.01-0.025$ & $0.025-0.05$ & $0.05-0.10$ & $0.10-0.25$ & $0.25-0.5$ & $0.5-1.0$ \\
\hline Percentage (\%) & 2.80 & 5.86 & 17.07 & 20.63 & 12.51 & 19.42 & 13.73 & 7.11 \\
\hline
\end{tabular}




\section{RESULTS AND DISCUSSION}

The hydrodynamic parameters investigated in this study include the mean flow velocity $(V)$, shear stress $(\tau)$, unit stream power (USP), Reynolds number (Re), Froude number $(F r)$, Darcy-Weisbach friction factor $(f)$, and Manning coefficient $(n)$. They can be calculated as follows:

$$
\tau=\gamma R J \quad U P S=V J \quad R e=V R / v \quad F r=V /(g d)^{0.5} \quad f=8 R J g / V^{2} \quad n=R^{2 / 3} J^{1 / 2} / V
$$

where $V$ is the flow velocity in $\mathrm{m} \mathrm{s}^{-1} ; R$ is the hydraulic radius in $\mathrm{m} ; J$ is the hydraulic gradient; $v$ is the water kinematic viscosity coefficient in $\mathrm{m}^{2} \mathrm{~s}^{-1}, v=0.01775 /\left(1+0.0337 \mathrm{~T}+0.000221 \mathrm{~T}^{2}\right)$ (where $\mathrm{T}$ is the water temperature at the stilling pound in ${ }^{\circ} \mathrm{C}$ ); $d$ is the flow depth in $\mathrm{m}$, and $g$ is the gravitational acceleration in $\mathrm{m} \mathrm{s}^{-2}$.

According to equation (1), the mean flow velocity $V$ is a basic hydraulic parameter, as Abrahams et al. (1986) pointed out. There are two standard procedures used to determine the mean flow velocity: (1) dividing the discharge by the cross-sectional area of the flow, and (2) timing the passage of a tracer (e.g. liquid dye) (Abrahams et al., 1986). The second procedure was employed in this study, that is, the average flow velocity was measured during each run using the dye-tracing technique with potassium permanganate. Other hydraulic parameters $(\operatorname{Re}, F r, \tau, U S P, n$, and $f)$ were then determined with equation (1).

\section{Dynamic flow variations}

Such variations can be described with mean flow velocity $(V)$, flow shear stress $(\tau)$ and flow unit stream power $(U S P)$. The results are shown in Fig. 2. According to Fig. 2, we obtained their coefficients of variation (CVs) for the different flow discharges of $Q=6,8,10,12$, and $14 \mathrm{~L} / \mathrm{min}$ to determine which variable is better to reflect the behaviour of dynamic flow variation. The CVs of $V$ are $0.095,0.106,0.172,0.168$, and 0.227 for $Q=6,8,10,12$, and $14 \mathrm{~L} / \mathrm{min}$, respectively. While the corresponding CVs are $0.236,0.344,0.282,0.451$, and 0.416 for $\tau$ and $0.477,0.507,0.452,0.464$, and 0.436 for $U S P$, respectively. The $U S P$ has the biggest $C V$ values indicating that the $U S P$ is more sensitive to the dynamic flow variations.

The $V$ is one of the most important hydraulic parameters for modelling soil erosion because it depends on the flow discharge, slope gradient, topography and surface condition (Zhang et al., 2002; Rahma et al., 2013). Furthermore, the gravitational force in the slope direction increases with slope gradient increase, which accelerates the flow velocity (and vice versa) (Gong, et al., 2011). The $\tau$ represents the energy dissipation of the flow toward the boundaries (Nearing et al., 1997). It is an important driver for removing soil particles by flow. The soil particles become detached and are transported down by runoff when the shear stress exceeds the cohesive properties of the soil particles. Flow detachment during erosion processes is often described using energy-based approaches (Lyle and Smerdon, 1965). Stream power or the USP is the energy of the flow that dissipates at the flow boundary (Nearing et al., 1997). It is a better predictor of soil detachment than the $\tau$ (Hairsine and Rose, 1992), which is consistent with the changing law of CVs from the USP. Some researchers have employed the USP instead of $\tau$ to describe sheet erosion and rill erosion on hillslopes (Moore and Burch, 1986). These studies agree with the results obtained in this study.

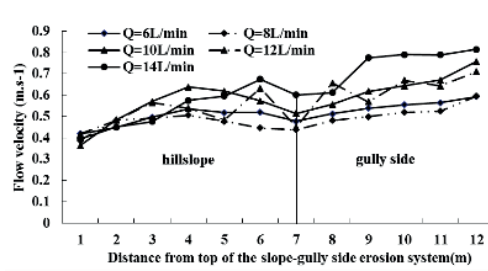

(a) Flow velocity

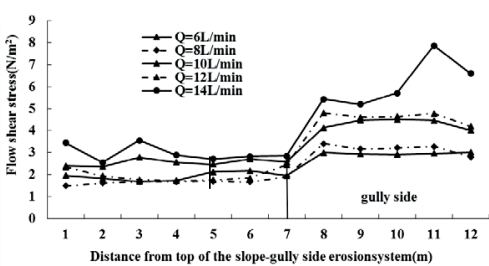

(b) Flow shear stress

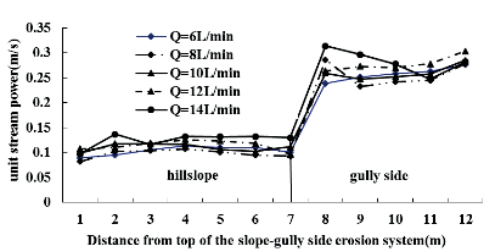

(c) USP

Fig. 2 Longitudinal variations of flow velocity, flow shear stress and flow unit stream power (USP). 


\section{Flow pattern variations}

It is important to characterize flow types in any erosion experiment that involves rills (Polyakov and Nearing, 2003). The Reynolds number $(R e)$ and the Froude number $(F r)$ are two critical hydraulic parameters for flow regimes.

$R e$ can be employed to determine whether the water flow is turbulent or laminar in terms of its specified critical value. In general, open channel flows are classified as turbulent when $R e>1000$, laminar when $R e<500$, and transitional when $500 \leq R e \leq 1000$. In this study, the $R e$ values varied from 342.3 to $551.81,404.5$ to $639.77,452.5$ to $769.6,541.26$ to 828.23 , or 609.46 to 858.8 when $Q=6,8,10,12$, or $14 \mathrm{~L} / \mathrm{min}$, respectively (see Fig. 3). Therefore, the runoff flow was laminar and transitional in the system during the entire experimental process.

On the other hand, the Fr is an important index for the state of water flow. It can be used to determine subcritical or supercritical flow and reflects the difference between the kinetic and potential energies of the flows. The runoff is considered as supercritical flow when $F r>1$, subcritical when $F r<1$, and critical when $F r=1$. In this study, the $F r$ values varied from 4.36 to 7.37, 2.99 to $6.95,2.15$ to $8.92,2.60$ to 7.78 , or 1.36 to 8.87 when $Q=6,8,10,12$ or $14 \mathrm{~L} / \mathrm{min}$, respectively (see Fig. 3). It means that the runoff during the test process was supercritical flow.

The frictional energy losses from the flows with bigger values of $\mathrm{Re}$ or $\mathrm{Fr}$ are greater than those with smaller $R e$ or $F r$ values. What is more, the frictional energy loss is closely related to the soil erosion, which has been confirmed in this study and other studies (Emmett, 1970; Abrahams and Parsons, 1994). Therefore, soil erosion in the slope-gully side system can be determined by observing the flow types of the system.

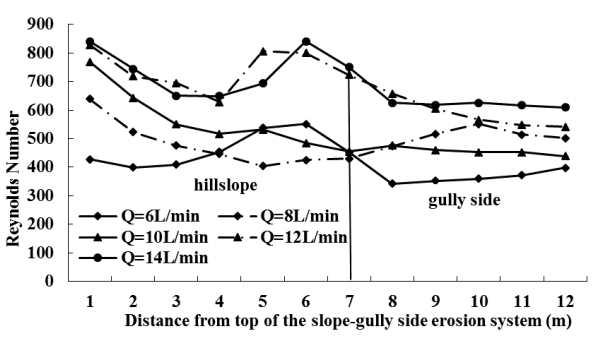

(a) $R e$

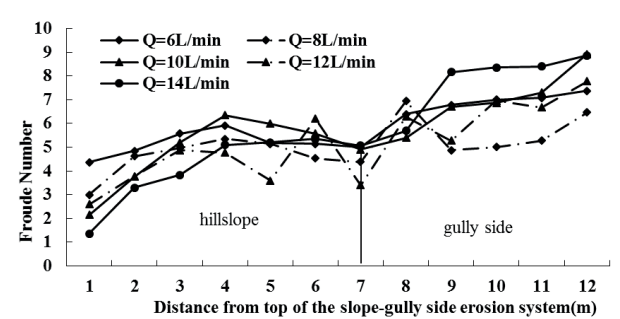

(b) $\mathrm{Fr}$

Fig. 3 Longitudinal variations of the Reynolds number $(R e)$ and the Froude number $(F r)$.

\section{Flow friction changes}

Two types of resistance, flow resistance and the resistance to erosion, play important roles in the soil erosion process. Resistance to erosion is important to sediment transport, which is usually quantified by cohesion or aggregate stability. Resistance to flow can be quantified with the Darcy-Weisbach and Manning equations.

The Darcy-Weisbach friction factor $(f)$ is often used as a parameter that represents the hydraulic resistance in overland flow studies that are conducted in the laboratory or field; while the Manning roughness coefficient $(n)$ is widely used as a parameter for channel flow in engineering and construction. However, both methods are based on the same main variables, including flow velocity and the water depth (Guo et al., 2013). Takken and Govers (2000) noted that the $n$ most likely behaves in the same way that the $f$ does, which is consistent with the results in this study (Fig. 4). Hessel et al. (2003) observed similar results from their studies on erosion from steep loess slopes. The reason for this is that both the $f$ and the $n$ reflect the size of the resistance encountered by the slope flow during the flowing process, which can be validated by the relationship between them $\left(n=0.0349 f^{0.4895}, \mathrm{R}^{2}=0.99\right.$, Table 2$)$. Under equivalent hydrodynamic flow rate and slope conditions, more energy is consumed to overcome the resistance to water flow when the resistance coefficient is greater. Thus, less energy is available for water erosion and sediment transport, which results in weaker soil erosion. In contrast, greater energy results in more sever soil erosion (Zhang et al., 2002). 


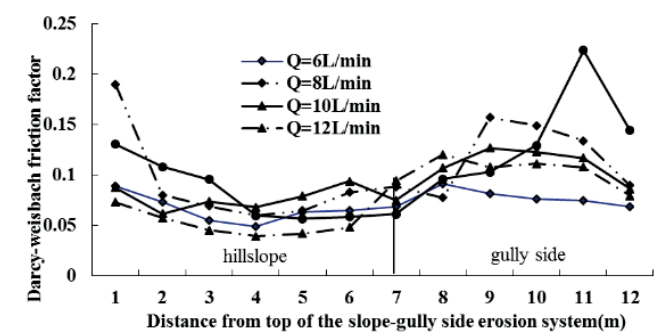

(a) Darcy-Weisbach friction factor

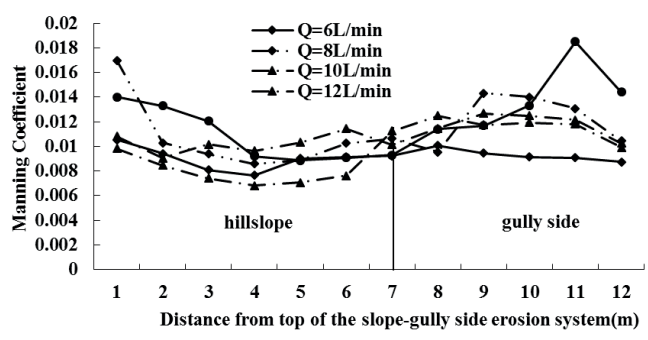

(b) Manning coefficient

Fig. 4 Longitudinal variations of Darcy-Weisbach friction factor and Manning coefficient.

\section{Relationships between the hydrodynamic parameters}

The correlations between the hydrodynamic parameters of the hillslope-gully side erosion system were analysed. The results are shown in Table 2 . These relationships in Table 2 are significant under 0.01 confidence level (2-tailed). Table 2 demonstrates that parameters of $F r, U S P, V, \tau, f$, and $n$ are closely related to $R e$ by different functions, so are $n$ to $f, V$ to $Q, \tau$ to $F r$ and $U S P$ to $F r$.

Table 2 Relationship with hydrodynamics parameters.

\begin{tabular}{lll}
\hline Hydrodynamics parameters set & Fitted relationship & \\
\hline$F r$ with $R e$ & $F r=2 \times 10^{8} R e^{-0.2752}$ & $\mathrm{R}^{2}=0.92$ \\
Unit stream power(m/s) with $R e$ & $U S P=4 \times 10^{9} R e^{-3.79}$ & $\mathrm{R}^{2}=0.69$ \\
Flow velocity $(\mathrm{m} / \mathrm{s})$ with $R e$ & $V=3607.4 R e^{-1.39} \quad \mathrm{R}^{2}=0.86$ \\
Shear stress $\left(\mathrm{N} / \mathrm{m}^{2}\right)$ with $R e$ & $T=-7.959 \ln (R e)+53.333 \quad \mathrm{R}^{2}=0.58$ \\
Darcy-Weisbach friction factor with $R e$ & $f=-0.293 \ln (R e)+1.9288 \quad \mathrm{R}^{2}=0.64$ \\
Manning coefficient with $R e$ & $n=-0.016 \ln (R e)+0.1134 \quad \mathrm{R}^{2}=0.61$ \\
Manning coefficient with Darcy-Weisbach friction factor & $n=0.0349 f^{0.4895} \quad \mathrm{R}^{2}=0.99$ & \\
Flow velocity $(\mathrm{m} / \mathrm{s})$ with flow discharge $(\mathrm{L} /$ min) & $V=0.0155 Q+0.405 \quad \mathrm{R}^{2}=0.8$ \\
Shear stress $\left(\mathrm{N} / \mathrm{m}^{2}\right)$ with $F r$ & $\tau=0.5921 F r^{-0.2044} \quad \mathrm{R}^{2}=0.63$ & \\
Unit stream power $(\mathrm{m} / \mathrm{s})$ with $F r$ & $U S P=0.0337 \exp (0.2815 F r) \quad \mathrm{R}^{2}=0.76$ \\
\hline
\end{tabular}

Some studies (e.g. Savat, 1980; Gilley et al., 1990; Nearing et al., 1997) have confirmed that the $f$ is closely related to the $R e$ for overland flow. In this study, the relationship between them $(f=$ $-0.293 \ln (R e)+1.9288, \mathrm{R}^{2}=0.64$; see Table 2 ) is significant under the 0.01 confidence level. It means that $f$ is also closely related to $R e$, which is consistent with the others studies (Savat, 1980; Gilley et al., 1990; Nearing et al., 1997). In some cases, the relationship curves between them may be different due to the different situations (such as soils, rainfalls and slopes). For example, Gilley et al. (1990) found that $f$ was related to $R e$ by a negative exponential function, which is different to the logarithmic function obtained in this study. It may imply that the relationship between the $f$ and the $R e$ in this study is just a special case. But to what extent the relationship between them is correct in the Chinese Loess Plateau is still unknown and needs further investigation.

At the same time, some parameters in Table 2 are confirmed to be closely related to the other ones by Savat (1980), Nearing et al. (1997) and Hessel et al. (2003). For example, Savat (1980) found that the hydraulic grain roughness decreased as the Re increased; Nearing et al. (1997) used sand and loess to study how $f$ changed with slope using a constant hydraulic radius and proved that $f$ decreased as Re increased; Hessel et al. (2003) had proved the $f$ and $n$ values can be estimated from the Reynolds number. These studies are accordant to our results shown in Table 2. In addition, some previous studies have indicated that flow velocity $(V)$ is related to flow discharge $(Q)$. For example, Govers (1992) showed that the flow velocity $(V)$ in rills that were eroding loose, non-layered materials could be predicted from discharge data in the absence of slope or soil effects, which was also confirmed by Nearing et al. (1997) and Giménez and Govers (2001). In this study, we obtained a linear curve between them $\left(V=0.0155 Q+0.405 \mathrm{R}^{2}=0.8\right.$; see Table 2$)$, which is agrees with the studies of Govers (1992), Nearing et al. (1997), and Giménez and Govers (2001). 


\section{CONCLUSIONS}

This study explored the flow spatial hydrodynamic variability of a hillslope-gully side erosion system through a series of lab-based experiments. The following conclusions can be drawn:

(1) The flow unit stream power (USP) has bigger coefficients of variation than the mean flow velocity $(V)$ and flow shear stress $(\tau)$. The USP is more sensitive to the dynamic flow variations and a better predictor of soil detachment than $V$ and $\tau$.

(2) The Reynolds $(R e)$ and Froude $(F r)$ numbers for the runoff indicate a significant variability between the different flows and slope positions. The runoff flow patterns were laminarsupercritical and transitional-supercritical in the system.

(3) Both the Darcy-Weisbach friction factor $(f)$ and the Manning roughness coefficient $(n)$ reflect the size of the resistance encountered by the slope flow during the flowing process. The $n$ most likely behaves in the same way that the $f$ does.

(4) The parameters of $F r, U S P, V, \tau, f$, and $n$ are closely related to $R e$ by different functions, so are $n$ to $f, V$ to $Q, \tau$ to $F r$ and $U S P$ to $F r$.

Acknowledgements This study was supported by the grants from the National Natural Science Foundation of China (Nos. 51109103 and 41001154) and the Fundamental Research Funds for the Central Universities of China (No. lzujbky-2014-126).

\section{REFERENCES}

Abrahams, A.D., Parsons, A.J. and Luk, S.H. (1986) Field measurement of the velocity of overland flow using dye tracing. Earth Surface Processes and Landforms 11, 653-657.

Bagnold, R.A. (1977) Bed load transport by natural rivers. Water Resources Research 13(2), 303-312.

De Ploey, J. (1983) Runoff and rill generation on sandy and loamy topsoils. Zeitschrift für Geomorphology, Suppl. Bd 46, 15-23. Emmett, W.W. (1970) The hydraulics of overland flow on hillslopes. US Geological Survey Professional Paper $662-\mathrm{A}, 68$.

$\mathrm{Fu}$, B.J., et al. (2011) Assessing the soil erosion control service of ecosystems change in the Loess Plateau of China. Ecological Complexity 8(4), 284-293.

Gilley, J.E., Kittwitz, E.R. and Simanton, J.R. (1990) Hydraulic characteristics of rills. Transactions of ASAE 33, $1900-1906$.

Giménez, R. and Govers, G. (2001) Interaction between bed roughness and flow hydraulics in eroding rills. Water Resources Research 37(3), 791-799.

Gong, J.G., et al. (2011) An experimental study on dynamic processes of ephemeral gully erosion in loess landscapes Geomorphology 125(1), 203-213.

Govers, G. (1992) Evaluation of transport capacity formulae for overland flow. In: A.J. Parsons and A.D. Abrahams (eds) Overland Flow: Hydraulics and Erosion Mechanics. London: UCL Press, 243-273.

Guo, T.L., et al. (2013) Flow hydraulic characteristic effect on sediment and solute transport on slope erosion. Catena 107:145-153.

Hairsine, P.B. and Rose, C.W. (1992) Modeling water erosion due to overland flow using physical principles: 1. Sheet flow. Water Resources Research 28, 237-244.

Hessel, R., Jetten, V., and Zhang, G.H. (2003) Estimating Manning's n for steep slopes. Catena 54, 77-91.

Lantican, M.A., Guerra, L.C. and Bhuiyan, S.I. (2003) Impacts of soil erosion in the upper Manupali watershed on irrigated lowlands in the Philippines. Paddy and Water Environment 1(1), 19-26.

Li, M., et al. (2009) Effect of grass coverage on sediment yield in the hillslope-gully side erosion system. Journal of Geographical Sciences 19(3), 321-330.

Lyle, W.M. and Smerdon, E.T. (1965) Relation of compaction and other soil properties to erosion resistance of soils. Transactions of the ASAE 8, 419-422.

Marques, M.J., et al. (2008) Soil degradation in Central Spain due to sheet water erosion by low-intensity rainfall events. Earth Surface Processes and Landforms 33(3), 414-423.

Merz, W. (1990) Threshold conditions for rill erosion of sandy loam Brunisols. MSc Thesis, Dept., Univ. of Toronto, Canada.

Meyer, L.D., Foster, G.D. and Nikolov, S. (1975) Effect of flow rate and canopy on rill erosion. Transactions of the ASAE 18, 905-911.

Moore, I. and Burch, G. (1986) Sediment transport capacity of sheet and rill flow: application of unit stream power theory. Water Resources Research 22(8), 1350-1360.

Nearing, M.A., et al. (1997) Hydraulics and erosion in eroding rills. Water Resource Research 33(4), 865-876.

Pan, C.Z. and Shangguan, Z.P. (2006) Runoff hydraulic characteristics and sediment generation in sloped grassplots under simulated rainfall conditions. Journal of Hydrology 331(1-2), 178-185.

Polyakov, V.O. and Nearing, M.A. (2003) Sediment transport in rill flow under deposition and detachment conditions. Catena 51(1), 33-43.

Rahma, A.E., et al. (2013) Measuring flow velocity under straw mulch using the improved electrolyte tracer method. Journal of Hydrology 495, 121-125.

Savat, J. (1980) Resistance to flow in rough supercritical sheet flow. Earth Surface Processes and Landforms 5, $103-122$.

Takken, I. and Govers, G. (2000) Hydraulics of interrill overland flow on rough, bare soil surface. Earth Surface Processes and Landforms 25, 1387-1402.

Zhang, G.H., et al. (2002) Soil detachment by shallow flow. Transactions of the ASAE 45 (2), 351-357. 